\title{
Comunicación
}

\section{Omentalización para el tratamiento de abscedación prostática en perros: dos casos clínicos}

\author{
OMENTALIZATION FOR THE TREATMENT OF PROSTATIC ABSCESSES IN DOGS: TWO CLINICAL CASES
}

\author{
Ysaac Chipayo G. 1,3, Carlos Huerta M. ${ }^{1}$, Juan Olazábal L. ${ }^{2}$, Diego Díaz C. ${ }^{1}$
}

\section{Resumen}

Se presentan los resultados de dos casos de omentalización prostática realizada en dos pacientes caninos que fueron diagnosticados con cuadros de abscedación prostática. La edad de los pacientes fue de 9 y 13 años. Presentaron fiebre, polaquiuria, decaimiento, anorexia y dolor abdominal. Las ecografías mostraron presencia de quistes/abscesos en la glándula prostática. La técnica quirúrgica se desarrolló de manera sencilla sin la necesidad de utilizar equipamiento complejo fuera del material quirúrgico básico. Los pacientes se recuperaron rápidamente del procedimiento quirúrgico sin observarse complicaciones pos-quirúrgicas. Se concluye que la técnica de omentalización prostática permite el tratamiento efectivo de abscesos intraprostáticos en perros.

Palabras clave: próstata; absceso; omentalización

\section{Abstract}

This paper presents the results of two cases of prostatic omentalization conducted in two canine patients who were diagnosed with prostatic abscess. The patients were 9 and 13 years old. They presented fever, frequent urination, decay, anorexia, and abdominal pain. The ultrasound showed presence of cysts/abscesses in the prostate gland. The

\footnotetext{
${ }^{1}$ Clínica de Animales Menores (CAMe), Facultad de Medicina Veterinaria, Universidad Nacional Mayor de San Marcos, Lima, Perú

${ }^{2}$ Laboratorio de Bioquímica, Nutrición Animal y Alimentación Animal, Facultad de Medicina Veterinaria, Universidad Nacional Mayor de San Marcos, Lima, Perú

${ }^{3}$ E-mail: ichipayo@hotmail.com
} 
surgical technique was developed in a simple manner without the need of using complex equipment outside the basic surgical material. Patients recovered quickly from the surgical procedure without having post-surgery complications. It is concluded that the technique of prostatic omentalization allows the effective treatment of intra-prostatic abscesses in dogs.

Key words: prostate; abscess; omentalization

\section{INTRODUCCIÓN}

La glándula prostática es la única glándula sexual accesoria del perro y circunda por completo la uretra desde el cuello vesical hasta la uretra membranosa pos-prostática. El epitelio glandular posee una barrera hemato-prostática que solo los antibióticos con alto grado de liposolubilidad pueden llegar a su parénquima (Basinger y Luther, 1996).

La infección prostática representa una condición clínica común en el perro. La fuente bacteriana es por lo general flora uretral normal (Basinger et al., 2003), pero también puede provenir de manera secundaria a orquitis, cistitis bacteriana, e incluso por vía hematógena (Klausner et al., 1995; Basinger et al., 2003). La disrupción de la arquitectura parenquimatosa por ocurrencia de hiperplasia prostática benigna, común en pacientes caninos, es un factor predisponente para la infección prostática, lo cual ocasiona la formación de quistes asépticos (Smith, 2008). Otros factores predisponentes son problemas en el flujo de orina, modificación de las secreciones prostáticas y alteraciones en el equilibrio hormonal que causan metaplasias escamosas en el interior del órgano (Basinger y Luther, 1996; Basinger et al., 2003). Los microabscesos que se van formando coalescen produciendo una abscedación parenquimatosa voluminosa. Las defensas del cuerpo intentan localizar los abscesos, pero pueden provocar la ruptura de la cápsula glandular y colaborar con la abscedación del órgano (Basinger et al., 2003). La ruptura de los abscesos puede provocar septicemia, peritonitis y colapso cardiovascular (Basinger y Luther, 1996; Dragonetti et al., 2005; Fossum et al., 2007).

La prostatitis supurativa con abscedación prostática se encuentra con cierta frecuencia en la clínica diaria. El tratamiento incluye antibioticoterapia prolongada y soporte nutricional e hídrico. En caso de abscedación prostática y sepsis se indica el avenamiento quirúrgico. Los métodos tradicionales como el drenaje de Penrose o la marsupialización de la glándula presentan complicaciones a largo plazo como prostatitis recurrentes, reaparición de los abscesos, infecciones e incontinencia urinaria, además de complicaciones sistémicas como hipoproteinemia, hipoglucemia, hipopotasemia y sepsis (Basinger y Luther, 1996; Basinger et al., 2003).

El omento mayor es una membrana serosa de gran tamaño (cubre la cavidad abdominal desde el estómago hasta la vejiga), dividida por los vasos sanguíneos que la irrigan en tres porciones: bursal, esplénica y el velo. Las dos primeras porciones presentan dos pliegues peritoneales, mientras que el velo solo presenta un pliegue peritoneal. El omento mayor esta irrigado por la anastomosis de las arterias gastroepiploica derecha e izquierda, de la arteria esplénica y de las diversas ramas de estos tres vasos (Doom et al., 2016). Una de las propiedades más importantes del omento es su capacidad de angiogénesis (Zhang et al., 1997). Se ha utilizado clínicamente para promover la cicatrización de heridas y para estimular la revascularización de los tejidos isquémicos (Zhang et al., 1997; Liebermann-Meffert, 2000; Platell et al., 2000; Rafael, 2008). El 
omento puede, además, realizar la función de absorción y eliminación de bacterias y material extraño en la cavidad peritoneal (Shimotsuma et al., 1993), por su capacidad de aporte de drenaje linfático. Se estima que alrededor del $90 \%$ de la actividad fagocitaria de la cavidad peritoneal se realiza en el omento (Van Vugt et al., 1996; LiebermannMeffert, 2000; Platell et al., 2000).

La omentalización prostática permite aprovechar las características fisiológicas del omento. La cirugía debe acompañarse de la castración del paciente. Este último es un procedimiento eficaz en el tratamiento de la prostatitis bacteriana, puesto que provoca la atrofia de la glándula y previene futuras recurrencias (Dragonetti et al., 2005; Fossum et al., 2007). El omento produce un suministro abundante de fibrina, que proporciona gran adhesión en zonas contaminadas y relleno cuando hay pérdida de tejido. Así mismo, la fibrina se organiza con el desarrollo de nuevos vasos sanguíneos y fibroblastos, para finalmente depositar colágeno y generar la formación de adherencias (LiebermannMeffert, 2000; Platell et al., 2000).

El objetivo del presente trabajo fue la presentación de dos casos clínicos de abscedación prostática y su resolución mediante la técnica de omentalización prostática.

\section{Casos Clínicos}

\section{Evaluación de los Pacientes}

El primer paciente fue un canino Pequinés de nueve años, macho, castrado un año antes. Ingresó a la Clínica de Animales Menores (CAMe) de la Facultad de Medicina Veterinaria de la Universidad Nacional Mayor de San Marcos (Lima, Perú) por presentar polaquiuria y tenesmo fecal, anorexia, depresión y vómitos. El animal pesó $6 \mathrm{~kg}$, con condición corporal $2 / 5$, temperatura $39^{\circ} \mathrm{C}$, deshidratación $6 \%$ y presentaba dolor a la palpación abdominal caudal.
Se realizó examen ecográfico de la zona abdominal con énfasis en el tracto genitourinario, encontrando múltiples estructuras quísticas hipo-ecogénicas en próstata (Figura 1). Se obtuvo una muestra por punción ecoguiada, recuperando un material aparentemente purulento, que fue remitida para análisis citológicos y bacteriológicos. En la citología se observó numerosos neutrófilos en diferentes grados de degeneración y microorganismos cocobacilares basófilos. En el cultivo fueron aislados Staphylococcus sp y Escherichia coli, sensibles ambos a ceftriaxona.

Los resultados ecográficos y del laboratorio confirmaron el cuadro de abscedación prostática, por lo que se inició un protocolo de tratamiento antibiótico con ceftriaxona. Se observó la rápida recidiva de los signos clínicos después de la punción de los abscesos y del tratamiento antibiótico. Se optó por la alternativa quirúrgica de la exploración drenaje y omentalización prostática.

El segundo caso fue un paciente Cocker Spaniel de 13 años, macho, entero, con historia clínica de haber sido tratado durante varios años por infecciones urinarias recurrentes. Llega a la CAME con signos de polaquiuria y orina de tonalidad verdosa. Presenta $16 \mathrm{~kg}$ de peso y temperatura de $40^{\circ} \mathrm{C}$. A la evaluación clínica se palpa una masa que se proyecta desde el canal pélvico hacia craneal, dolorosa durante la evaluación.

Se realizó una evaluación ecográfica y se tomó una muestra de orina mediante punción de pared abdominal para cultivo (Peña et al., 2013). En la ecografía se observa la próstata con pequeñas estructuras redondeadas (quistes), además de dos estructuras ovaladas, anecoicas, de 6.26 x $2.77 \mathrm{~cm}$ y $7.44 \mathrm{x}$ $2.96 \mathrm{~cm}$, con bordes irregulares (Figura 2). El cuadro es compatible con hiperplasia prostática benigna y/o prostatitis severa con quistes y abscesos prostáticos. El testículo derecho presentó estructuras redondeadas, ecogénicas y homogéneas, compatibles con 
neoplasias. En el cultivo de orina se aisló Escherichia coli sensible a sulfadoxinatrimetropin, amikacina, ceftriaxona y amoxicilina con ácido clavulánico.

Se hizo una punción ecoguiada que confirmó la presencia de abscesos intraprostáticos. Valorando los antecedentes de infecciones recurrentes, se optó por la alternativa quirúrgica del drenaje y omentalización prostática y castración.

\section{La Técnica Quirúrgica}

Se aplicó la técnica de omentalización prostática en ambos pacientes (White y Williams, 1995). Los pacientes fueron sometidos a una laparatomía umbilico-púbica parapeneana para realizar el abordaje prostático (Figura 3A). Se colocó un catéter uretral para facilitar la palpación de la uretra en el interior del parénquima prostático y evitar lesionarla. Se aislaron la vejiga y la próstata de la cavidad abdominal mediante la colocación de paños de tercer campo humedecidos con solución fisiológica. Se realizó la divulsión del tejido para-prostático y el reconocimiento de las márgenes de la próstata y de las estructuras quísticas (Figura 3B).

Se realizaron dos inciso-punciones en las regiones ventro-laterales de la próstata y se procedió al drenaje de los abscesos con ayuda de una bomba de succión conectada a un equipo de venoclisis estéril. Una vez vaciados los abscesos, se procedió a la disección roma con pinza hemostática de Halsted en dorsal y ventral a la estructura uretral para lograr la coalescencia de los abscesos. Se tunelizó la próstata por dorsal y ventral de la uretra (Figura 3C) (Basinger et al., 2003; Fossum et al., 2007; White, 2009).

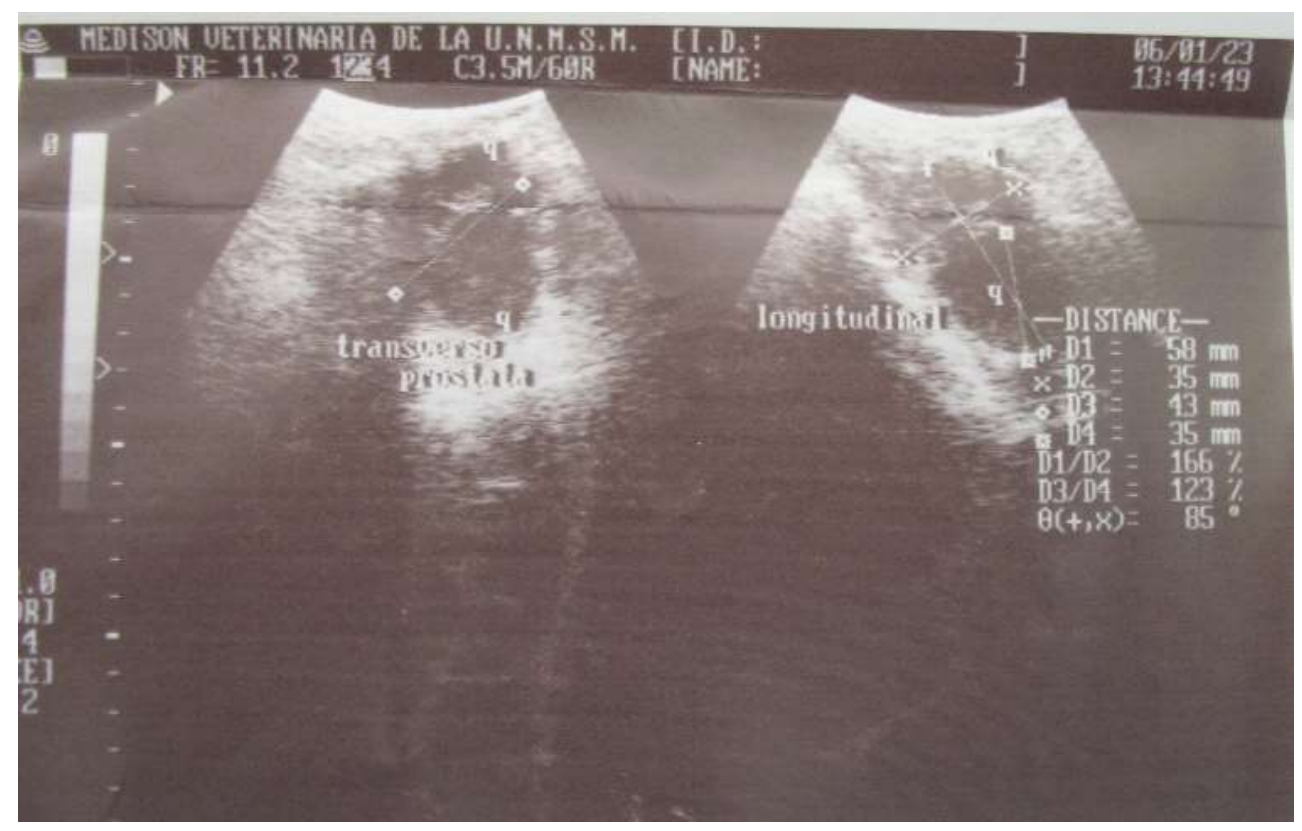

Figura 1. Imagen ecográfica de la próstata del paciente 1 


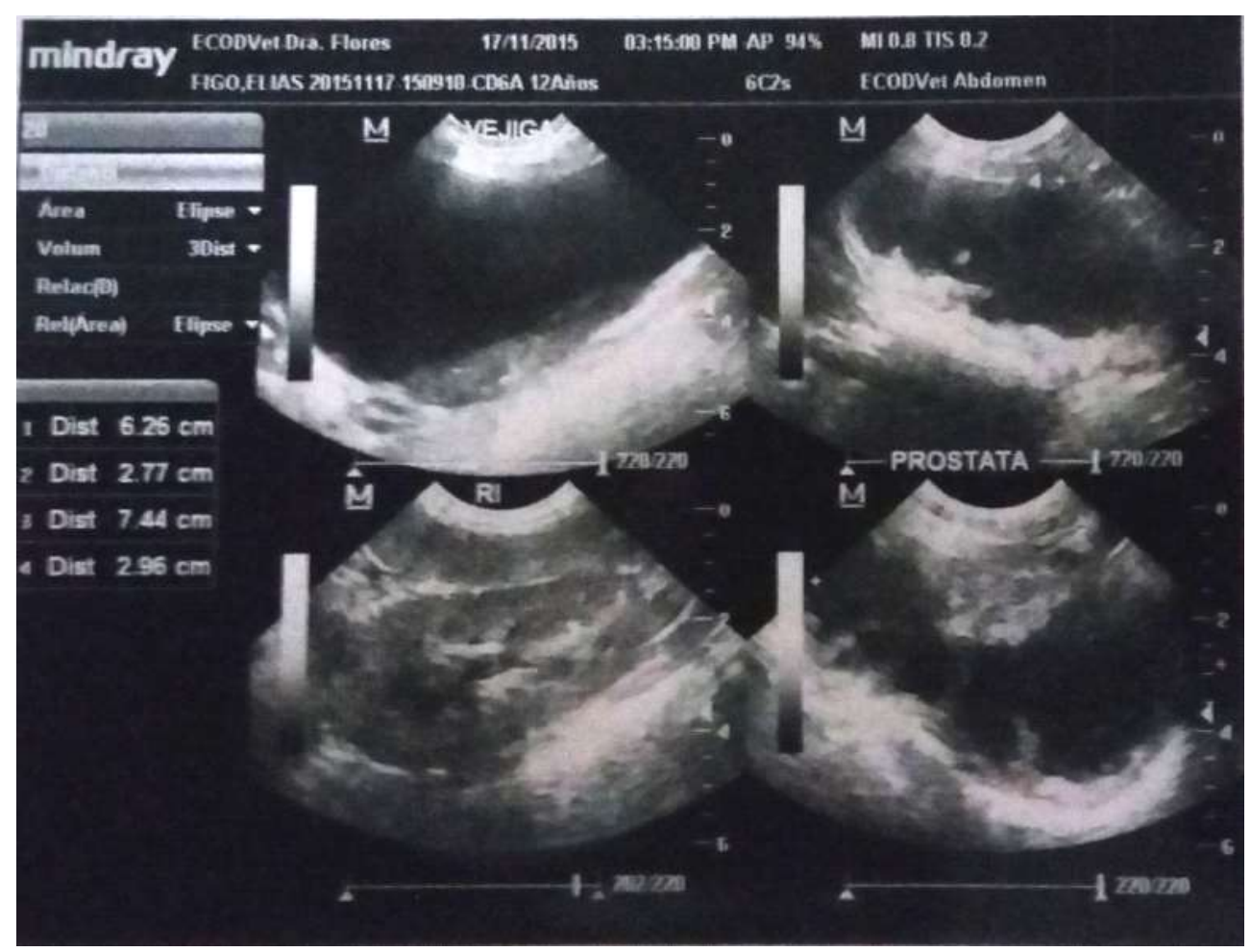

Figura 2. Imagen ecográfica de próstata y vejiga del paciente 2

Se realizaron múltiples lavados con solución salina estéril para diluir los contaminantes durante los procesos de drenaje y divulsión del parénquima prostático y evitar su diseminación en la cavidad abdominal. Se colocó una hebra de nylon a través del aspecto dorsal y ventral de la uretra por los túneles creados después de la divulsión y coalescencia de los abscesos prostáticos. Se preparó un pedículo de omento mayor para colocarse a través del túnel realizado en la próstata guiada mediante la tracción con la sutura de nylon precolocada (Figuras 3D y $3 E)$. Finalmente se colocaron puntos de sutura que fijaron el omento a sí mismo, una vez que se logró que el pedículo circunde la uretra y vuelva a salir de la estructura prostática.

El proceso de preparación del pedículo de omento se realizó sin mayores complica- ciones. El manejo del omento, la incisión de los márgenes del pedículo y el control de las hemorragias se realiza de manera sencilla y sin la necesidad de equipamiento especializado, utilizando solo el material quirúrgico general. Además, el pasaje del colgajo de omento creado se puede realizar de manera sencilla, de modo que todo el procedimiento quirúrgico, en ambos casos, no superó los 30 minutos.

Los pacientes mostraron una rápida recuperación pos-quirúrgica. Los signos clínicos mostrados se corrigieron de manera rápida, observándose mejora del apetito y de la conducta al tercer día de la cirugía. En la evaluación clínica y ecográfica de los pacientes en los días 15 y 45 posquirúrgicos no se observó señal alguna de recidivas de los abscesos prostáticos. 


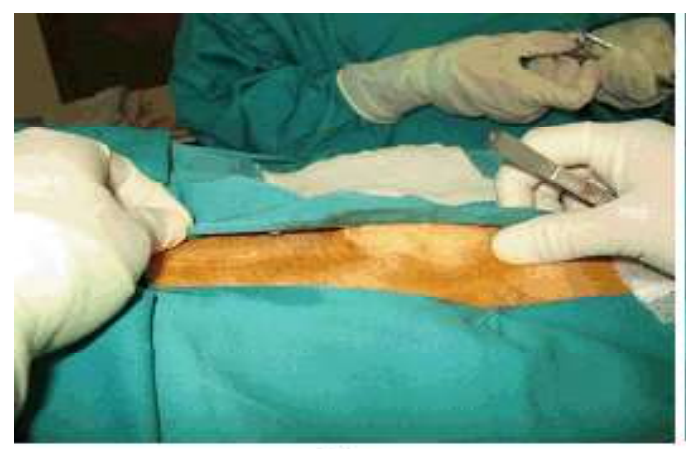

(A)

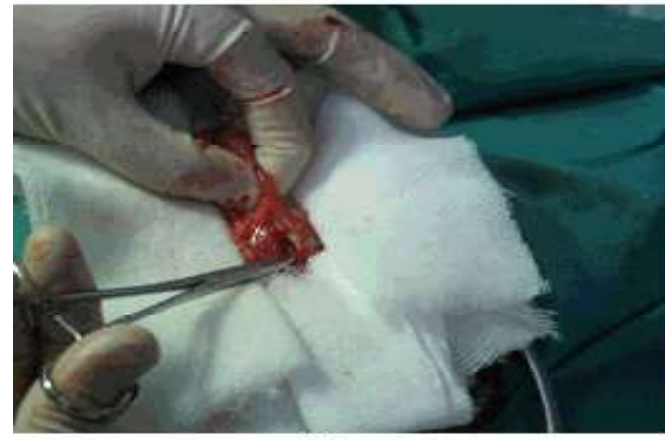

(C)

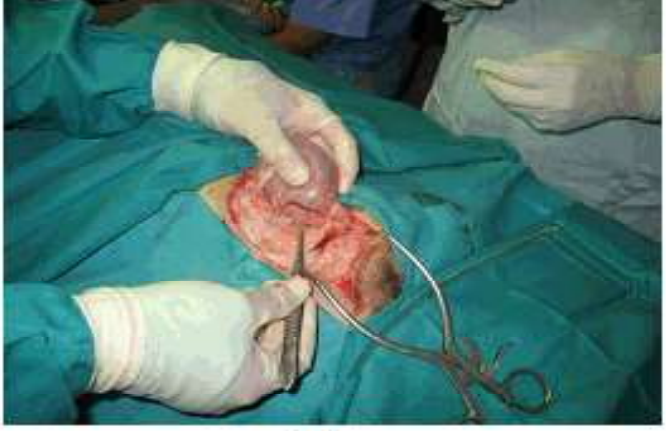

(B)

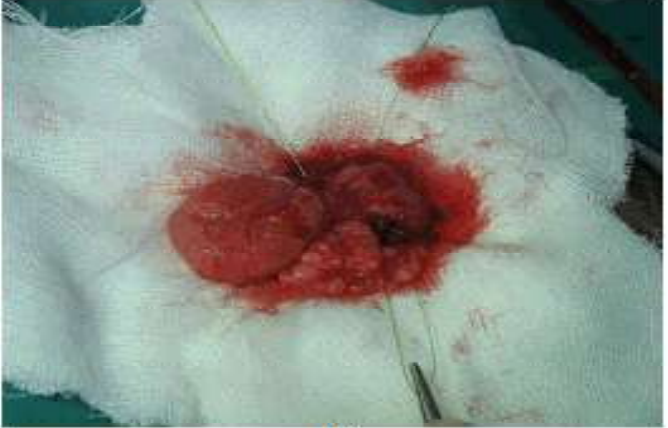

(D)

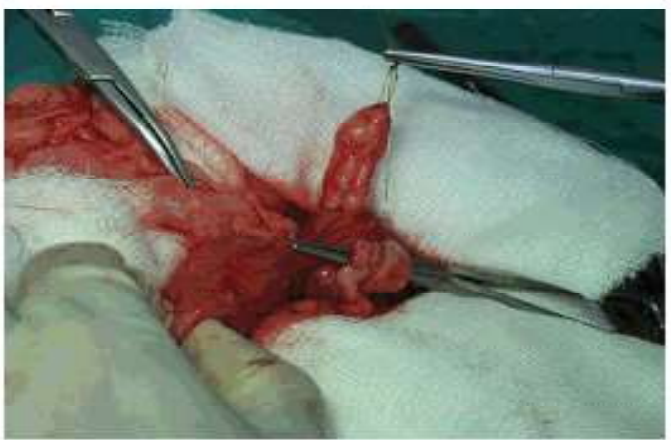

(E)

Figura 3. Omentalización prostática. (A) Delimitación del área cutánea para la incisión. (B) Reconocimiento del tejido peri-prostático. (C) Divulsión intra-capsular con pinza hemostática. (D) Colocación del hilo de nylon que servirá de guía al omento. (E) Pasaje del colgajo de omento a través de la próstata y alrededor de la uretra

\section{Discusión}

En la literatura médica se disponen de alternativas quirúrgicas de corrección de la abscedación prostática en caninos. Las técnicas de mayor discusión y aplicación son el drenaje de Penrose, la marsupialización y la omentalización. En este estudio se constató que la omentalización es una técnica que aprovecha las bondades propias del omento (Shimotsuma et al., 1993; LiebermannMeffert, 2000; Platell et al., 2000; Rafael, 2008; Villanueva, 2012). Al colocar el omento dentro de la próstata, una vez tunelizada y drenado los abscesos, se adhiere al parénquima prostático permitiendo la eliminación de los quistes/abscesos al absorber las 
secreciones que se forman, logrando una total recuperación al favorecer la formación de vasos sanguíneos que transporten con facilidad macrófagos y medicamentos (Rafael, 2008).

Una ventaja de esta técnica, al aprovechar el omento, es que no necesita dejar aberturas en la pared abdominal para drenar los contenidos de los abscesos, que pueden provocar mayores infecciones y que requiere de protocolos de monitorización intrahospitalaria y de tratamiento médico más complejo. La técnica de omentalización prostática en casos de abscedacion prostática representa una técnica quirúrgica que no necesita equipamiento tecnológico complejo que encarecen el procedimiento quirúrgico, ni las necesidades de tratamiento y hospitalización posquirúrgica como en el caso de la marsupialización o colocación de drenajes de Penrose, y que puede ser desarrollada de manera sencilla como medio terapéutico quirúrgico definitivo.

\section{Literatura Citada}

1. Basinger R, Luther P. 1996. Enfermedad prostática. En: Bojrab M (ed). Fisiopatología y clínica quirúrgica en animales pequeños. $2^{\mathrm{a}}$ ed. Argentina: InterMédica. P 555-561.

2. Basinger R, Robinette C, Spaulding K. 2003. Prostate. In: Slatter D (ed). Textbook of small animal surgery. $3^{\text {rd }}$ ed. Philadelphia PA, USA: Saunders. p 15421557.

3. Doom M, de Rooster $\mathrm{H}$, van Bergen T, Gielen I, Kromhout K, Simoens P, Comillie P al. 2016. Morphology of the canine omentum Part 1: arterial landmarks that define the omentum. Anat Histol Embryol 45: 37-43. doi: 10.1111/ ahe. 12168

4. Dragonetti A, Solis C, Giordano A. 2005. Prostatitis en el perro. Analecta Vet 25: 33-39.
5. Fossum T, Hedlund C, Johnson A, Schulz K, Seim III H, Willard M, Bahr A, Carrol G. 2007. Small animal surgery. $3^{\text {th }}$ ed. USA: Mosby Elsevier. $1632 \mathrm{p}$.

6. Klausner JS, Johnston SD, Bell FW. 1995. Canine prostatic diseases. In: Kirk RW. Current veterinary therapy XII. Philadelphia, PA, USA: WB Saunders. p 1103-1108.

7. Liebermann-Meffert D. 2000. The greater omentum. Anatomy, embryology, and surgical applications. Surg Clin North Am 80: 275-293. doi: 10.1016/S00396109(05)70406-0

8. Peña S, Chavera A, Cahua J, Perales $R$. 2013. Alteraciones prostáticas en caninos determinadas mediante ultrasonografía y citología por aspiración eco-guiada. Rev Inv Vet Perú 24: 207-216. doi: 10.15381/rivep.v24i2.2502

9. Platell C, Cooper D, Papadimitriou J, Hall J. 2000. The omentum. World J Gastroenterol 6: 169-176. doi: 10.3748/ wjg.v6.i2.169

10. Rafael H. 2008. Aplicación clínica del epiplón en el sistema nervioso central. Acta Med Per 25: 176-180.

11. Shimotsuma M, Shields J, SimpsonMorgan M, Sakuyama A, Shirasu M, Hagiwara A, Takahashi T. 1993. Morpho-physiological function and role of omental milky spots as omentumassociated lymphoid tissue (OALT) in the peritoneal cavity. Lymphology 26: 90-101.

12. Smith J. 2008. Canine prostatic disease: a review of anatomy, pathology, diagnosis, and treatment. Theriogenology 70 : 375-383. doi: 10.1016/j.theriogenology.2008.04.039

13. Van Vugt E, Van Rijthoven E, Kamperdijk E, Beelen R. 1996. Omental milky spots in the local immune response in the peritoneal cavity of rats. Anat Rec. 244: 235-245. doi: 10.1002/ ( S I C I ) 1097 - 0185 (199602) 244:2<235::AID-AR11>3.0.CO;2-Q

14. Villanueva A. 2012. La omentalización en cirugías gastrointestinales: estudio- 
experimental en conejos. Tesis de Médico Veterinario. Lima: Univ. Nacional Mayor de San Marcos. 57 p.

15. White R. 2009. Aparato urogenital masculino. En: Williams J., Niles J (ed). Manual de cirugía abdominal en pequeños animales. UK: British Small Animal Veterinary Association. p 371-373.

16. White RA, Williams JM. 1995. Intracapsular prostatic omentalization: a new technique for management of prostatic abscesses in dogs. Vet Surg 24: 390-395. doi: 10.1111/j.1532-950X.1995.tb01349.x

17. Zhang QX, Magovern CJ, Mack CA, Budenbender KT, Ko $W$, Rosengart TK. 1997. Vascular endothelial growth factor is the major angiogenic factor in omentum: mechanism of the omentummediated angiogenesis. J Surg Res 67: 147-154. doi: 10.1006/jsre.1996.4983 